\title{
Resilience Among Single Adult Female Refugees in Hamilton, Ontario
}

\author{
Karen Chung, Ellie Hong, and Bruce Newbold
}

\begin{abstract}
Single adult females remain among the most vulnerable of all refugee populations. However, there is a lack of research on supporting and empowering these women. There is a new interest in identifying factors that reinforce resilience and, ultimately, adjustment to the host country. In line with the current work on resilience, semi-structured, indepth, personal interviews with single refugee women were conducted in the city of Hamilton, Ontario. A grounded theory approach revealed participants' perspectives on the support received from religious or cultural communities, non-governmental organizations, and the government in terms of their perceived contribution to adaptation. Both informal and formal support, along with individual characteristics, were found to be crucial for reinforcing resilience among these refugees, reflective of a collective resilience model that moves beyond individual and community resilience. Future research should aim to investigate the perspectives of those who did not receive social support from shelters as well as to assess the efficacy of current refugee support services.
\end{abstract}

\section{Résumé}

Les femmes adultes célibataires demeurent parmi les plus vulnérables des groupes de réfugiés. On remarque cependant un manque de recherches sur le soutien et l'autonomisation de ces femmes. Il y a par ailleurs un nouvel intérêt pour l'identification des facteurs augmentant la résilience et par conséquent la capacité d'ajustement au pays d'accueil. En lien avec ces travaux sur la résilience, des entrevues individuelles approfondies et semi-structurées avec des femmes réfugiées célibataires ont été effectuées à Hamilton en Ontario. L'approche basée sur la théorie a mis en lumière leur point de vue sur le soutien qu'elles reçoivent des communautés culturelles et religieuses et des organisations gouvernementales et non-gouvernementales, plus particulièrement au niveau de leur adaptation. Le soutien formel et informel, en plus des caractéristiques personnelles, s'avèrent être des facteurs importants pour l'amélioration de leur résilience, illustrant un modèle de résilience qui va au-delà de la résilience individuelle et des communautés. Les recherches à venir devraient examiner la perception des réfugiés qui n'ont pas reçu de soutien social et évaluer l'efficacité des services actuels de soutien aux réfugiés.

\section{Introduction}

Internationally, there has been a sustained increase in the number of people who seek refuge from harm in their home country. ${ }^{1}$ Although Canada prides itself on its humanitarian role and acceptance of refugees, there is comparatively limited research evidence surrounding the needs of refugees, as well as their ultimate success in adaptation to the host country. Indeed, a systematic review of published research on Canadian refugee health emphasizes the urgent need to fill the gaps of health knowledge for refugee populations, including the refugees' perspective on factors that ease their relocation. ${ }^{2}$

The limited research on refugees in the host country context typically focuses upon the barriers to health care encountered by refugees that limit or slow their adaptation to the host country. ${ }^{3}$ While these barriers are relatively well understood, there is a new interest in identifying the 
strengths or features that promote resilience and, ultimately, adjustment to the host country, rather than focusing on problems, risks, and failures. This is what is referred to as an asset-focused model: factors that support the ability for refugees to overcome barriers and that promote more successful integration to the host society. ${ }^{4}$ Much of this work is conducted through the concept of resilience. While there are varying definitions of resilience, it can be broadly defined as "a class of phenomena characterized by the ability to bounce back and cope effectively in spite of serious threats to adap-

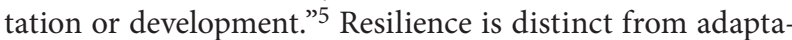
tion: it refers to a refugee's ability to resist serious stress during the process of adapting to a new community. Although many refugees are likely to have experienced war, political instability, physical/sexual violence, death of family or friends, and multiple displacements across refugee centres, ${ }^{6}$ there is significant optimism about the capacity of refugees for resilience to trauma and dislocation. ${ }^{7}$ As Pulvareti and Mason note, "Resilience is often said to be about bending, not breaking, when facing stress, trauma and adversity." 8

To date, however, much of the work has searched for individual protective factors, ${ }^{9}$ rather than identifying it as a collective process, ${ }^{10}$ leading to calls for moving research away from a focus on individual resilience toward recognition of the role of multiple factors, including group composition, institutions, non-governmental agencies, and public policies. ${ }^{11}$ As an alternative, "collective resilience" 12 differs from individual resilience (personal resilience) and community resilience (resilience in one community). While individual attributes remain important, collective resilience allows the exploration of the broader structures that bridge and hold communities while providing support and enable resettlement, including support from the wider society, particularly contributions "from community members; people from the same country of origin or people who share values; respect for each other; empathy and support of local people; and community members talking, negotiating, discussing and balancing their needs and views." ${ }^{3}$

Within collective resilience, the community can provide assets, including support networks, infrastructure, and resources that empower and create participation. Social support from within the community, including shared vision, mutual assistance, cooperation, and attachment, has been noted to aid resilience and adaptation to the host society. For example, social support, including strong religious beliefs, engenders increased psychological well-being in refugees. ${ }^{14}$ In building community support, more people gain support from the community, reinforcing the process, and ultimately aiding adjustment and resettlement in a circular and cumulative process. Conversely, if social support is missing, resilience may be lower and resettlement slower.
For example, single adult females remain among the most vulnerable of all refugee populations, ${ }^{15}$ with differences including origin, journey, health status, language ability, refugee status, and culture having different impacts on how these women will adapt to the host country. ${ }^{16}$ Social and community supports may be missing or cannot be accessed owing to limited opportunities and barriers that prevent support access. Such risk factors, inclusive of the individual or community, can reduce or deny individual opportunities and prevent meaningful participation in the community.

In order to understand these similarities and differences as well as the factors that promote resilience, narratives from refugee women are needed. The objective of this study is to share the perspectives of single, low-income refugee women on factors that encourage successful adaptation into new communities by examining how resilience is promoted, reinforced, or grown among refugee women in Hamilton. It is our hope that this will be a stepping stone for policy advocates and invested stakeholders to gain a more comprehensive awareness of relevant public policies, forms of social support, and more appropriate resource allocation.

\section{Background}

Hamilton, Ontario, is a mid-sized Canadian city located in southern Ontario, about sixty kilometres west of Toronto. The city has an estimated 500,000 residents, including a foreign-born population greater than 100,000. Approximately 1,440 refugees arrive annually in Hamilton; around 440 are government-assisted refugees (GAR), while 1,000 are refugee claimants or individuals who claim refugee status after arrival in Canada. ${ }^{17} \mathrm{Up}$ to one-third of all foreign-born within the city entered Canada as refugees, representing a greater proportion of all immigrants than observed for all Ontario or all Canada, with Hamilton's refugees arriving from a diverse set of origins. Due to its proximity to Toronto and its lower cost of living, Hamilton is also an important centre for "secondary" settlement of refugees (i.e., settling in Hamilton after an initial settlement elsewhere).

Prior to changes to refugee health care (enacted by the Canadian federal government in June 2011), both refugee claimants and GARs were eligible for health coverage through the federal government's Interim Federal Health Program (IFH). ${ }^{18}$ Following a three-month residency period in the province, GARS could also apply directly to the provincially funded Ontario Health Insurance Plan (OHIP) which provides more extensive health coverage. ${ }^{19}$ In comparison, IFH is a temporary health insurance program (twelve months, with options for extending up to twenty-four months for recipients with identified special health needs ${ }^{20}$ ) that covers urgent and essential health needs including prenatal, contraception, and obstetrical 
care; essential prescription medications; emergency dental treatments; and treatment and prevention of serious medical conditions. Counselling or psychotherapy, diagnostic procedures, certain ambulance services, and vision care are also covered to an extent but required preapproval from Citizenship and Immigration Canada. GARS also receive access to resettlement services (funded through the federal government) which provide services including health, employment, language, and settlement. Refugee claimants, on the other hand, are not eligible for IFH and are also unable to access settlement and integration services until they have attained permanent status (i.e., until their refugee claim has been approved).

Refugees commonly arrive in Canada with greater health, social, and economic needs than other immigrants: a significantly greater proportion of refugees report physical, emotional, or dental problems than all other immigrants. One reason for this is that refugees are much more likely to have experienced war, political instability, physical/sexual violence, death of family or friends, and multiple displacements across refugee centres. ${ }^{21}$ Refugee women suffer in strikingly different ways than men upon arriving in Canada, and are particularly vulnerable to mental health issues during resettlement. ${ }^{22}$ Due to the subordinate role of women in many cultures, they are at greater risk of facing exposure to violence, lack of or reduced autonomy, lack of recognition of foreign credentials and experience, cultural and systematic barriers to care, poverty, underemployment, the burden of multiple roles within the family, social isolation, and loss of pre-existing social support. Single and low-income women may face even greater barriers than married women because they often arrive without any pre-existing forms of social support. ${ }^{23}$ Cultural norms that govern women's roles in social situations may render it difficult for them to become part of larger refugee communities: this isolation may heighten risks of sexual and gender-based violence, including sexual exploitation and forced prostitution. ${ }^{24}$ As a result, they are more likely to experience low income and to be among the most vulnerable.

While these barriers to successful acculturation exist, there may be resources and opportunities that promote resilience and ultimately enable individuals to overcome barriers. Formal services such as government programs, settlement services, immigrant groups, and informal forms of support such as religious and cultural communities may all facilitate resilience for these women. This paper will consider these forms of support from the perspectives of single refugee women.

\section{Methods}

This research paper aims to examine how resilience is promoted, reinforced, or grown among low-income single refugee women in Hamilton. In order to assess this, formal support received from government agencies, NGOs, and religious organizations, along with informal support from family and from religious and cultural communities, were evaluated through their experiences. The strength, positive attitude, and resourcefulness of these refugee women were also assessed. Both were accomplished through personal, semi-structured interviews of single adult female refugees of childbearing age, eighteen to fifty years.

Refugee women who arrived in Hamilton within the period of one month to ten years before the study date of September 2011, with an annual income below the 2010 Statistics Canada low-income cut-off, were recruited to the study. Approval was gained from the author's institutional Research Ethics Board (REB) before proceeding with the recruitment process. Study recruitment flyers were translated prior to recruitment into Czech, Hungarian, Arabic, and Spanish. The interviewees were recruited with the help of three community service centres in Hamilton. These centres were contacted in advance to request permission to place study recruitment posters in traffic-heavy areas. With further permission from administrative members from these centres, administrative staff recruited interviewees by word of mouth.

A total of nine interviews between September and December 2011 were conducted. The women interviewed came from diverse backgrounds including Hungary, Nigeria, Iraq, Cameroon, Afghanistan, Sudan, and Congo, with three out of the nine interviews requiring a professional translator to be present at the interview. Prior to each interview, interviewees were given a consent form and notified that they could withdraw from the study at any point, which would in turn lead to the deletion of any recorded information. A recording device was used during the interview to record the interview proceedings. An interview guide was used to facilitate responses from interviewees, whereby a combination of open- and closed-ended questions were used. The interview script included questions addressing their life prior to arrival, the arrival and settlement process, their experience with social, educational, and health services in Canada, support used and received (inclusive of family, friends, and providers), and sources of fear and stress upon coming to Canada and settlement. After the interview, interviewees were provided with a small token of appreciation for participating in the study, consisting of two bus passes and a $\$ 20$ grocery gift card.

Interviews lasted an average of fifty-five minutes and were transcribed for a total of twenty-four hours verbatim, 
and their content was analyzed. Transcripts were marked with a number that replaced the interviewee's name to ensure confidentiality, and to identify which recorded information must be deleted in the event that a given interviewee wished to withdraw from the study. As this was an exploratory study, the research did not attempt to test existing theories. ${ }^{25}$ Instead, a grounded theory approach was used during the coding process to facilitate understanding about resilience. ${ }^{26}$ Grounded theory enables theory generation related to social processes "grounded" in empirical data and the experiences of participants, ${ }^{27}$ with the resulting theory able to inform research and interventions. Data collection and analysis occurred simultaneously, with each transcript coded for themes relating to resilience. These themes were placed in categories based on the source/type of resilience identified, and then further broken into subcategories reflecting participants' experiences of those barriers. Common themes within and across groups were identified through the coding process and further discussed by the authors for relevance and significance.

\section{Results}

The narratives of these single, low-income refugee women reveal how resilience was promoted through informal sources, NGOs, government support, and personal characteristics such as their resourcefulness, determination, and strength. Most strikingly, all participants were dependent on all of these supports in order to meet their needs, reflecting notions of collective resilience, although some services were seemingly more important than others.

All but one of the women interviewed for this project were single when they arrived in Canada, either having separated from their husbands or having been widowed before arrival in Canada. The one woman who arrived in Canada with her husband later separated from him after arrival and prior to the interview. Most (six) brought young children with them. Most came directly to Canada from their home country; others transited through other countries before arriving in Canada. Six came directly to Hamilton after landing in Canada, while the others transited or temporarily resided in other Canadian cities before arriving in Hamilton. Once in Hamilton, all used temporary accommodation (typically refugee shelters) for their first few weeks in the city before finding their own accommodation, often with the assistance of the shelter, friends, or community groups.

All of the interviewees were unemployed at the time of the interview and received their income from the provincial government through the Ontario Works program. Most were taking, or had taken, ESL courses to strengthen their English ability, and two volunteered in the local community. Despite the circumstances that they found themselves in-single mothers, low income, living in a new community, and reliant on the government for income support-their resilience was apparent: more than just adapting to their new life, the resilience among the women interviewed for this project was enhanced by various assets within the community. The discussion below explores why.

\section{Support from the Government}

Although education is not a direct avenue of support, refugee women interviewed for this study saw education, which is funded through the provincial government, as an instrumental factor in securing their long-term success in Canada. The single female refugees who arrived with children were very pleased with the educational support provided by the government. Seeing their children transition to life in Canada aided by the educational system gave these women hope and motivated them to attain educational success as well. Following the educational experiences of her children, one woman commented: "I know but I want education now. Because for me this is important, I can't work all my life in McDonald. For the future, I want a good job" (5).

The education system also provided a significant source of hope to these women. Many of these women came from occupations they were interested in pursuing after settlement in Canada. "I have master degree in English language teaching, but I cannot get a job in Egypt, here they said you can go to Mohawk degree, they say you can work at least as a teacher in any organization here" (3).

However, like many below the low-income cut-off, these women struggled with the financial and health services provided by the government. All of these women arrived with little financial resources, having spent most of their savings to get to Canada. Thus, although the women were grateful for whatever the government could provide, the struggle to gain financial resources and access to health care eroded resilience and made it difficult for these women to adapt.

I get paid \$334 from Ontario Works, \$200 for rent. It's not enough, food and groceries are very expensive. $\$ 200$ is just good for the food. For one month, $\$ 800$, not enough. Internet, home, it's not enough. And other bills are lots. It's good child tax give me $\$ 1000$, with this I manage the house. But you don't have no choice. (5)

Being part of the workforce is crucial to resilience through the creation of long-term sense of belonging and community. One woman expressed feelings of frustration from not being able to obtain a job of a similar status to what she had in her home country because of her lack of Canadian experience. Not being able to find a job decreased her sense of belonging: 
Because if you read in the Immigration Canada website, they promise you everything, they promise you everything. They promise you a job. But when you come here you realize that the jobs here are less than the people. And the jobs that are menial jobs, 8 to 10 dollars, minimum wage. It's not something I want to do. I did these a student, but I didn't expect to do it here now in Canada, with all my qualifications I thought I could get a job. But no, they told me that I don't have a Canadian experience. So that is the barrier that we are facing. (4)

Beyond employment, good health and access to health care when needed are critical to resilience promotion. As noted in McKeary and Newbold, ${ }^{28}$ lack of access to health care remains a concern among refugees in particular and newcomers to Canada more generally. Surprisingly, and despite the fact that other researchers and providers alike have noted consistent issues with the IFH, ${ }^{2}$, refugees did not discuss the role or need of health insurance and the program. For some, they had not needed to venture into the health care system, or had not been in Canada long enough to have received coverage through the provincial health plan. For those that had used the health care system, community groups or shelters had helped to facilitate finding a doctor and/or they persevered in finding health care. Still, one-third of respondents did not know what IFH was and did not know how it worked.

\section{Support from NGOs}

Government support for refugee health care (i.e., through the IFH program) or other services is limited both temporally as well as financially, forcing refugees to seek assistance with settlement from other organizations or communities. Non-governmental organizations (NGOs) enhance resilience by providing refugee women not only with the resources that they need to adjust to living in Canada (i.e., access to language services, shelter, food, and other services), but also with connections and opportunities to become established and enhance their resilience by building personal assets.

Language support has been identified as a significant barrier to health care and other services following arrival. NGO support included English language training, mental health, and employment assistance. NGOs also provided refugees with access to better shelter, child services, transportation, food, and clothing, and are often critical supports for refugees by filling in the blanks that government programs do not provide:

Yeah when I came to [the community centre] that night, they said oh no problem, you sleep here, you stay here, so they gave me food, and gave me bed, before that I showered, hadn't showered in 2 weeks, got up in the morning and showered. I didn't have any clothes, so I got taken to the warehouse and got myself some clothes. (4)

Oh it was, I, I, thank God it was good! The most important thing for me is shelter, the shelter and the food. That's what is important, you have this for your kids, your kids when they say I'm hungry and there is nothing, your heart is break. You know? But there's food, there's shelter. ...they give us the food and the shelter. (6)

We actually got contact information from the shelter to get in touch with a person where we can get help with navigating, and planning appointments, and just helping us with the settlement process. We got a lot of help that was very helpful. (1)

Mental health issues remain a concern within the population and are vital for resilience, as many refugee women have come from a place of war and political instability, while being subjected to physical and sexual abuse. However, only three of the nine interviewees mentioned that they had used some form of counselling. This is in line with current evidence that Western mental health services are often underutilized because they are "culturally alien to most refugees, the majority of whom come from non-Western societies and bring with them culturally specific ways of understanding and responding to psychological distress." ${ }^{30}$ NGOs are crucial support networks that can help these refugee women overcome emotional and psychological challenges that may prevent their successful adaptation: "Yeah, Oh [the community centre people] are very good people, you know they helped me to, to you know, move from my trauma and get past that" (7).

This support is important, because when these women arrive in Canada, some of them still struggle from the trauma that they have experienced as refugees. In addition, many of these women miss their families and their friendsand find it difficult to adapt to the reality that they may never see them again.

While NGOs help refugees manage, the assistance is often only short term. For some of our participants, shelter was provided for the period of one year by NGOs, after which their eligibility for support ended. When the year finishes, these participants needed to move out and find shelter and furniture for a permanent place to live:

\footnotetext{
The home that we're in is only for one year, it's not ours. Ours no, but they provide for us a dinner table, couch and chairs and they put bed and drawers and they helped me a lot because they put bed and everyone tells me they look for bed and mattress and stuff and now after we stay here...kitchen, everything I got, blankets I got, jacket I got. (7)
} 
NGOs provide important support and assets by providing resources, education, encouragement, and support to refugees, all of which built resilience. At the same time, support from NGOs is often limited, forcing refugees to find other forms of support. While it is reasonable to expect that support should be withdrawn at some point after arrival, the termination of support at one year appears to be arbitrary, and threatens resilience given that it often takes longer than a single year to adjust to the host community.

\section{Informal Support from Religious or Cultural Communities}

Community, and more importantly community assistance and support for refugees, is an important component of resilience. For new arrivals, creating or participating in a community is vital and provides support and a sense of belonging through attachment and place. At the same time, community enhances resilience by providing coping mechanisms through social networks, infrastructure, education, encouragement, support, and resources and can create opportunities that encourage meaningful participation in the community. However, such community must be built, as most refugees lost a large degree of their social network, including family, in coming to Canada. Likewise, community does not occur naturally, and must be nurtured through contributions by community members, shared values, and engagement. Consequently, refugees needed to rely on a range of individuals for their social network, inclusive of others sharing their same origin or ethnic background as well as the broader community who provided opportunities to discuss problems with adjusting to Canadian life.

Regardless of the process that brings newcomers to Canada, the existence of religious, ethnic, or cultural communities is generally seen as an advantage and enabler of social and economic acculturation to the host society. Cultural background plays a major role in the informal support that a refugee woman may receive. Like many newcomers, the refugee women sought emotional and informational support from peers, relatives, and friends established in Canada. ${ }^{31}$ Most newcomers viewed those who came to Canada before them as an important source of support because they had first-hand knowledge of Canadian society, customs, and the settlement process. ${ }^{32}$

From Egypt, there is somebody there. He helped me, he's like my translator? Yeah, he helped me a lot, he came to me, we came to Niagara Falls, anyways he helped me, he came to me over there, he helped me, we stayed with a friend for two three days and we came to the [community centre] house. (7)
The women also relied upon their religious community to help overcome barriers to health and language:

I have friends, before I don't have friends, now I have gotten friends, I have pastor that talk to me, I have church that come to visit me. They bring so many things for me. Each time they come they bring so many things for me. They bring clothes for my baby, for my son, only that because I'm too fat, sometimes they say that they will bring things for me, only that because I'm too fat, they don't have my size you know? They can't find my size in their wardrobe. But for my kids, for my little baby, for my son, they bring things for them. My house is full you know? They call me on phone and talk to me, do you have any you know, do you need things? (2)

While providing material and social support, the religious community helped to build community, enable settlement, and integrate refugees in the community, and often linked them into the broader community beyond their own, potentially more narrowly defined, ethnic group. Ethnic or cultural communities filled a similar role in providing both short-term support as well as long-term assistance that contributed to resilience. Importantly, resilience wasn't something that just happened, but reflected a process that unfolded over time and through interaction with various agents and providers. Refugees who came from cultural backgrounds previously established in Hamilton had an advantage in that connections into the community could be easier and access to NGOs and other forms of support were facilitated. Oftentimes, these community members understood their challenges and empathized with them. ${ }^{33}$ "And they make a contact here-the Sudanese people they met me and at the border when I crossed the border they met me and... we went to that shelter" (7).

Being understood, and having a community in which to relate their experiences, allowed these refugee women to improve upon their coping mechanisms and fostered a sense of belonging. However, there are also refugees from cultural backgrounds that are not as well established in Hamilton. Many miss their families and their friends, and find it difficult to adapt to the reality that they may never see them again. Some participants found life lonely and isolating given the lack of a pre-existing refugee community, and especially because their cultural understanding of community differed drastically from that found in Hamilton. For example, many women were born and raised in small communities with lots of family and where friends were considered family too. These women found it difficult to adapt to a community of strangers: "And back home too, always something happening with aunts and grandma, but 
here-there's no one ... and they told me, "don't knock on anybody's door" (6).

Thus, participants revealed that this form of support lead to a more successful acculturation, while a lack of a cultural or religious community seems to have a negative impact on resilience.

Other informal forms of support included family and the social environment of the community. Of the nine single refugee women that were interviewed, only three arrived without children. Participants with children described them as a source of social support and motivation for life:

I'm very happy with my life. Thank God I have my kids. I'm happy, I'm going on. I don't need anything else. For me my kids is important. This, everyday is going on. Life goes on. Just stand up and say I'm happy. You need to keep yourself strong. I think this was bad happening to me, I'm done now, because I have two more kids. My job, I go on, for my kids. I'm going on for my kids. I want to be both mother and father. (5)

Furthermore, almost all agreed that the community in Hamilton was supportive, open, welcoming, and respectful:

It was good. Over here, in Canada everything is available. Healthy, the country is helping the women for the food and the services. This is good. For us culture, if women is single and divorced with kids, no one give them clothes or food. There are no services. These women and kids die on the road. This place is a $100 \%$ better than our countries. Good services, good school. This experience is healthy experience for women especially. (5)

I have so many that talk to me, my doctor is the first person.... I have friends, before I don't have friends, now I have gotten friends, I have pastor that talk to me, I have church that come to visit me. They bring so many things for me. Each time they come they bring so many things for me. ... They call me on phone and talk to me, do you have any you know, do you need things? Does your daughter need anything? Sometimes I say, it's okay my house is full, I don't need anymore, they say Sabina you need! Your daughter need! Brittney is growing! And I have a friend, she gets me things wow, very, very well. When I was in my house she always came to visit me-even now she came to visit me, call me on phone. Okay, so they care, people care for me, they want me to live! (7)

It was specifically noted that there was a lack of racial discrimination in Hamilton, a factor which could reduce resilience by creating barriers to the broader community. ${ }^{34}$

...I like to talk about the experience with people. Because where we come from, no one says hi to us because of our origin. This is not a problem here, because everyone says hi and smiles. There is no problem here. (1)

Support from family and a welcoming environment typically encouraged resilience by promoting a positive approach to life. Thus, these forms of informal support meet emotional, informational, material, and social needs, greatly contributing to successful acculturation in a new community.

\section{Strength, Positive Attitude, and Resourcefulness of the Women}

Interviews with refugee women identified that resilience is both conditional upon the assistance of the broader community and also constructed through the support of community, agencies, family, and friends. Refugees clearly valued the support that they received from service providers, including help that was timely, relevant, and reflective of community strengths. Fundamental to resilience, but also beyond formal and informal support, each interviewee demonstrated incredible courage and strength, not only with their decision to come to Canada, but in how they dealt with challenges upon arrival. These difficulties included, but were not limited to, discrimination, food, language, work, culture, and lack of financial resources. Though the challenges that many of these women faced were daunting, their strength, positive attitude, and resourcefulness showed that they are capable individuals, able and willing to contribute to the community. Furthermore, the women demonstrated great resourcefulness as they were not reliant on just one group, but rather used a combination of resources provided by the government, NGOs, and cultural organizations in order to succeed. The ability to ask questions underscores their resilience:

\footnotetext{
"So how were you able to learn about the bus system?"

"Because I am always asking. I keep asking." (2)
}

as well as the ability to manage their lifestyle and spending habits:

747 dollars...it's not enough, you consider, internet, rent, TV. It's not enough. I try to manage. (3)

Moreover, there was a sense of independence among the refugee women interviewed, especially refugee women with children:

I wanted to depend on myself, I don't want everyone doing for me like a baby, you know no! But like you know they give me and they 
say its' your responsibility, yeah but they tell you, they advise you know? How to do-and then it's for you. (6)

For me it's easy, I'm a mother, it's normal. (5)

Not only were the refugee women able to manage given the few resources provided, but they also many maintained a positive attitude despite the language, resettlement, and cultural barriers they encountered:

Now, thanks God thanks God thanks God... Before I came here I was crying, you know? But now I look at it and say thanks God, thanks God we came here and everything here is better, different life, different, different life, different life different everything. What do you want more? (2)

I'm very happy with my life. Thank God I have my kids. I'm happy, I'm going on. I don't need anything else. You should be going on. If sometime bad is coming, you don't want to stand up and say I'm done. You can't be like that. You need to keep yourself strong. (5)

Thus, these refuge women, through their optimism, strength, and determination, were able to foster a sense of collective resilience by drawing upon the resources that they embodied, but also by drawing upon the community resources. This is turn acted to promote their successful acculturation into the broader Hamilton community.

\section{Discussion}

This research paper sought to explore how resilience is reinforced among refugee women in the Hamilton community. The ability of these women to adapt is dependent on who they are (internal), as well as on the external supports (assets) available in their community. Refugees are, by nature, a resilient group, given the traumatic experiences they encountered before finding a way to come to Canada. ${ }^{35}$ As such, individual strengths and traits are necessary, but not sufficient, for resilience. Instead, resilience extends to the broader community "collective," including an individual's ability to draw on various assets for support: government services, NGOs, and informal religious and cultural communities: all provided education, encouragement, and support that enabled resilience by allowing them to cobble together sufficient resources to allow them to manage and overcome barriers. It can be said that it is the ability to "manage" what they have that underscores a successful acculturation. Resilience also appears as a process-it is not something that necessarily has a defined start or end point, but continues as settlement occurs, new languages are learned, and lives are reconstructed through new opportunities.
The assets supporting resilience and integration into the host society are collective and are reinforced by the strength, positive attitude, and resourcefulness of the women, enabling this vulnerable population to manage despite the challenges and difficulties they are faced with. ${ }^{36}$ Collective resilience, encompassing support from government agencies, NGOs, and informal sources, was crucial in creating and reinforcing resilience among refugee women. More than just aiding their adaptation to their new country, these sources of support allow the ability to overcome barriers to adaptation by drawing upon their own strengths while also connecting the women to a larger community and knowledge of the resources that are embedded within it. That is, promotion and building of resilience will aid adaptation.

However, not all assets were equally strong. Government support, for example, appeared limited to programs such as Ontario Works and access to some services including health care through the IFH program, meaning that NGOs were consequently forced to pick up what is not covered by the government. Support from NGOs provided the women with access to language services, shelter, food, services for their children, and transportation information; however the support is often short-term and limited to GARs, while refugee claimants are largely forced to find their own way. In other words, the support provided by NGOs is only as good as those provided by more formal institutions, and refugee claimants are forced to rely on these multiple sources of support.

Likewise, support through social networks, such as religious or cultural communities and peer and family support, enabled resilience and is an influential factor of emotional and physical health. ${ }^{48}$ However, not all social networks were supportive or well established, with some commenting on their still developing networks, while others noted the difficult time immediately after arrival when they had no one. Without a sense of community and belonging, feelings of rejection and depression can often persist, ${ }^{37}$ while establishing proper support networks will help promote resilience among refugee women and ultimately allow them to contribute and thrive in their adopted communities.

Social capital cannot, on its own, substitute for more formal resources. Instead, such facilitating and positive sources of resilience are most effective when available together. However, resilience supporting assets can be withdrawn and/or weakened, jeopardizing resilience and integration. In 2011, for example, the Canadian federal government significantly reduced health coverage for refugee claimants. ${ }^{38}$ Likewise, a major settlement service closed in the years prior to this work. Although other agencies had stepped in to cover the missing services, overall funding was reduced and the loss of the one provider demonstrated 
the frailty of the system. Such examples highlight the many funding reductions and program restructuring with respect to refugees, with cuts affecting the most vulnerable. NGOS are unlikely to have sufficient resources to fill the new gaps that emerge. Instead of cutting funding towards refugees, more programs that address the unique challenges experienced by refugees in Hamilton (and likely elsewhere) need to be made available, with funding for programs reflecting the long period of adaptation to the host country-a period that cannot be neatly defined by a single year. If the refugees interviewed in our study are reflective of the broader refugee population and arrive in Canada having experienced trauma and the distress of relocation to a strange land, this would include tackling sources of emotional or psychological distress upon arrival, along with counselling services.

Throughout the interviews, measures were in place to maintain objectivity. We remained aware of the assumptions we made regarding the barriers with accessing proper health care, finding proper housing, receiving proper education, and eating healthfully. However, a limitation of this study was that the administrative staff members from the two community service centres were the ones actively recruiting the interviewees. This may have biased the administrative staff members to select interviewees that had received the best support from their service agency. As a result, the interviewees chosen for the study may have had a much more positive outlook on given social services than what might be representative of the entire population of single refugee women in Hamilton, Ontario. A second limitation was that this study only recruited interviewees through community service centres. Thus, refugees who were not able to receive this form of support (inclusive of claimants) were not included and their perspectives should be taken into account in future investigations. Finally, there is the concern that the limited number of participants may not reflect the refugee women in the community. Although the sample size is relatively small, it should be noted that participants were recruited until data saturation was reached. Future research should aim to investigate the perspectives of those who did not receive social support from shelters as well as to assess the efficacy of current refugee support services.

\section{Notes}

1. United Nations, "Refugees, Resources for Speakers on Global Issues," http://www.un.org/en/globalissues/ briefingpapers/refugees/nextsteps.html; S. Martin, "Refugee and Displaced Women: 60 Years of Progress and Setbacks," Amsterdam Law Forum 3 (2011): 72.
2. C. L. Patil, T. Maripuu, C. Hadley, and D. W. Sellen, "Identifying Gaps in Health Research among Refugees Resettled in Canada," International Migration (2012), doi:10.1111/j.1468-2435.2011.00722.x).

3. M. McKeary and K. B. Newbold, "Barriers to Care: The Challenges for Canadian Refugees and Their Health Care Providers," Journal of Refugee Studies 23 (2010): 523-545; J. Naish, J. Brown, and B. Denton, "Intercultural Consultations: Investigation of Factors That Deter Non-English Speaking Women from Attending Their General Practitioners for Cervical Screening," British Medical Journal 309 (1994): 1126-1128.

4. M. Pulvirenti and G. Mason, "Refugee Women's Experiences of Violence and Resilience: Early Explorations," Australian and New Zealand Critical Criminology Conference, 2010, http://ses.library.usyd.edu.au/bitstream/2123/7377/1/ Mason\%20and\%20Pulvirenti_ANZCCC2010.pdf.

5. M. A. Sossou, C. D. Craig, H. Ogren, and M. Schnak, "A Qualitative Study of Resilience Factors of Bosnian Refugee Women Resettled in the Southern United States," Journal of Ethnic and Cultural Diversity in Social Work 17 (2008): 365-385.

6. Pulvirenti and Mason, "Refugee Women's Experiences of Violence and Resilience: Early Explorations."

7. A. Fielding and J. Anderson, "Working with Refugee Communities to Build Collective Resilience" (ASeTTS Occasional Paper 2, ISBN 174067587 8), http://asetts.vacau .com/Documents/collectiveresilenceweb.pdf.

8. Pulvirenti and Mason, "Refugee Women's Experiences of Violence and Resilience: Early Explorations."

9. S. Luthar, D. Cicchetti, and B. Becker, "The Construct of Resilience: A Critical Evaluation and Guidelines for Future Work," Child Development 71 (2000): 543-562; T. A .P. Witmer and S. M. Culver, "Trauma and Resilience among Bosnian Refugee Families: A Critical Review of Literature," Journal of Social Work Research 2 (2001): 173-187.

10. S. Mohaupt, "Review Article: Resilience and Social Exclusion," Social Policy and Society 8 (2008): 63-71.

11. Pulvirenti and Mason, "Refugee Women's Experiences of Violence and Resilience: Early Explorations."

12. Fielding and Anderson, "Working with Refugee Communities to Build Collective Resilience."

13. Ibid.; Martin, "Refugee and Displaced Women."

14. R. Schweitzer, F. Melville, Z. Steel, and P. Lacharez, "Trauma, Post-migration Living Difficulties, and Social Support as Predictors of Psychological Adjustment in Resettled Sudanese Refugees," Australian and New Zealand Journal of Psychiatry 40 (2006): 179-187; J. Ahern, S. Galea, W. G. Fernandez, K. Bajram, R. Waldman, and D. Vlahov, "Gender, Social Support and Posttraumatic Stress in Postwar Kosovo," Journal of Nervous and Mental Disease 192 (2004): 762-770; M. Brune, C. Haasen, M. Krausz, O. Yagdiran, E. Bustos, and D. Eisenman, "Belief Systems as Coping Factors for Traumatized Refugees: A Pilot Study," European Psychiatry 17 (2002): 451- 458. 
15. Martin, "Refugee and Displaced Women"; Z. Deacon and C. Sullivan, "Responding to the Complex and Gendered Needs of Refugee Women," Affilia 24 (2009): 272-284.

16. Beth Dewitt and Naomi Adelson, "Toward Equitable Health and Health Services for Cambodian Refugee Women: An Ethnographic Analysis," http://pi.library.yorku.ca/dspace/ bitstream/handle/10315/10248/AdelsonDewitt2005 .pdf? sequence $=1$; McKeary and Newbold, "Barriers to Care."

17. S. Wayland, "A Demographic Profile of Immigrants to Hamilton" (Hamilton: Hamilton Immigration Partnership Council, 2010).

18. Citizenship and Immigration Canasda, "Interim Federal Health Progream: Summary of Benefits," http://www.cic .gc.ca/english/refugees/outside/summary-ifhp.asp.

19. The Canadian federal government enacted major changes to the IFH following data collection and analysis. We raise the potential implications of this policy change in the conclusion.

20. J. Wales, "Interim Federal Health: A Public Health Perspective," McMaster University Medical Journal 7 (2010): 50-52.

21. K. E. Miller and L. M. Rasco, The Mental Health of Refugees: Ecological Approaches to Healing and Adaptation (Mah Wah, NJ: Lawrence Erlbaum Associates, 2010).

22. V. Crooks, M. Hynie, K. Killian, M. Giesbrecht, and H. Castleden, "Female Newcomers' Adjustment to Life in Toronto, Canada: Sources of Mental Stress and Their Implications for Delivery Primary Mental Health Care," GeoJournal 76 (2011): 139-149.

23. Deacon and Sullivan, "Responding to the Complex and Gendered Needs of Refugee Women."

24. Martin, "Refugee and Displaced Women"; Deacon and Sullivan, "Responding to the Complex and Gendered Needs of Refugee Women."

25. M. Cope, "Coding Qualitative Data," in Qualitative Research Methods in Human Geography, 2nd ed, ed. I. Hay (Toronto: Oxford University Press, 2005); K. G. Esterberg, Qualitative Methods in Social Research (Boston: McGrawHill, 2002);

26. J. Corbin and A. Strauss, Basics of Qualitative Research: Techniques and Procedures for Developing Grounded Theory, 3rd ed. (London: Sage, 2007).

27. D. Walker and F. Myrick, "Grounded Theory: An Exploration of Process and Procedure," Qualitative Health Research
16 (2006): 547-559; H. Starks and S. Brown Trinidad, "Choose Your Method: A Comparison of Phenomenology, Discourse Analysis, and Grounded Theory," Qualitative Health Research 17 (2007):1372-1380.

28. McKeary and Newbold, "Barriers to Care."

29. Ibid.

30. Miller and Rasco, The Mental Health of Refugees.

31. M. Stewart, J. Anderson, M. Beiser, E. Mwakarimba, A. Neufeld, L. Simich, and D. Spitzer, "Multicultural Meanings of Cultural Support amongst Immigrants and Refugees," International Migration 46 (2008): 123-159.

32. Ibid.

33. Ibid.

34. S. Edge and K. B. Newbold, "Discrimination and the Health of Immigrants and Refugees: Exploring Canada's Evidence Base and Directions for Future Research in Newcomer Receiving Countries," Journal of Immigrant and Minority Health, DOI 10.1007/s10903-012-9640-4. 2012.

35. J. Hooberman, B. Rosenfeld, A. Rasmussen, and A. Keller, "Resilience in Trauma-Exposed Refugees: The Moderating Effect of Coping Style on Resilience Variables," American Journal of Orthopsychiatry 80 (2010): 557-563.

36. C. L. Dennis and L. Ross, "Women's Perceptions of Partner Support and Conflict in the Development of Postpartum Depressive Symptoms," Journal of Advanced Nursing 56 (2006): 588-599.

37. P. A. Thoits, "Mechanisms Linking Social Ties and Support to Physical and Mental Health," Journal of Health and Social Behaviour 52 (2011): 145-161.

38. These changes were announced and put in place following the completion of the data gathering stage of this project.

Karen Chung and Ellie Hong were students in McMaster University's Health Sciences program.

Bruce Newbold (corresponding author) is a professor in the School of Geography and Earth Sciences at McMaster University. Trained as a population geographer, his research focuses on health and settlement issues among immigrants to Canada. This research was funded by the Canadian Institutes of Health Research (CIHR, \#86517). 